Interdisciplinary Research in Education

Volume 4, Issue 2, 2019: i-iii

DOI: https://doi.org/10.3126/ire.v4i2.29697

\title{
Multidisciplinary issues of education in Nepal
}

Amidst the growing debates on educational approaches, policies and programs in developing countries, multiple issues have drawn the attention of policymakers and practitioners. Such issues cut across the academic disciplines and move beyond the formal structure of curricula, pedagogies, assessment practices and school systems as a whole. In Nepal, a top-down approach to policy-making, political party influence in policy decisions and the donor-driven agenda play a dominant role in shaping educational policies and reforms. Rather than drawing on the issues informed by the local research studies, educational reform discourses are largely influenced by political party interests and the global policy agenda promoted by multinational and supranational donor organizations. As Nepal has just undergone a political transition from a constitutional monarchy to a federal political structure, there is a pressing need for formulating educational policies to address the local needs from multiple subject areas. In the context of global-local tensions, in general, and the federal-provincial tension, in particular, educational researchers need to contribute to knowledge that informs both the local level policy-making processes and the existing practices in schools. This volume of Interdisciplinary Research in Education incorporates the research studies that contribute to expanding the existing knowledge in Nepal's educational policy discourses and reform plans.

In the first article, Dhruba Prasad Niure analyzes the converging and diverging issues of indigenous and formal education systems. Guided by the interpretive-constructivist research paradigm, followed by a case study design, he discusses how Tharu teachers and students build on the indigenous knowledge system. His study reveals that both formal and indigenous education systems have their own educational goals and curricula, and both of them impart specific sets of knowledge and skills to the learners by using multiple instructional techniques. Nevertheless, both education systems are not identical to each other in terms of learning environment, skills, nature of learning, types of teachers, medium of instruction, and assessment tools. As a result, Tharu children's academic performance, in the formal education system, falls below the expected level, compared to the performance of their non-indigenous friends. His study has suggested that the formal curricular contents should be made compatible with indigenous knowledge systems to make it relevant for the indigenous children.

In the second article, Shambhu Prasad Khatiwada analyzes the status and barriers to effective use of classroom-based student assessment practices for Geography teachers at secondary levels. With data from both communities and institutional schools from different Provinces as well as ecological zones, his research concludes that the majority of Geography teachers still use traditional means of student assessment practices, such as terminal exams, halfyearly exams, and annual exams. While some teachers are found using both the paper-pencil test and classroom-based student assessment practice in general and particular in Geography subject, 
this number is not significant. The classroom-based student assessments such as homework, classwork, group discussion and project work are an integral part of Geography teaching.

Badri Nath Bhatta's article, third in this Volume, provides an overview of how prosperity has been achieved through tourism and what educational implications we can draw from the local tourism practices through a case study done in Ghalegau Lamjung. This article first introduces tourism through an anthropological outlook which is followed by a brief explanation of the efforts in tourism in Nepal from both government and non-government sides. With the general introduction of study areas and methods, this article then provides a detailed explanation of development and changes in the society through tourism and educational implications and lessons learned from the local practices. In conclusion, Bhatt asserts that tourism is a potential source of the national economy and through education we can explore and promote our hidden treasures, historic places and cultures.

The next two articles in this volume contribute to mathematics and ICT education. Bed Raj Acharya explores the perception and practices of teachers on the assessment system in mathematics education at Tribhuvan University. Using an interpretive research approach, and collecting data from the students, teachers, head teachers and resource persons of Gorkha, Nuwakot and Kaski districts, his analysis indicates that the existing assessment practices are formative in nature which include project work, classwork, extracurricular activities and field visits, group discussions, and weekly tests, among others. He suggests that local knowledge and cultural practices should be included in the student assessment system and that teachers should be provided with subject-specific training for assessing students' performance. In addition, he argues that effective monitoring systems should be developed and appropriate reference materials related to testing should be available for the teachers. Arjun Neupane, in another article, assesses students' views in using Moodle in teaching mathematics. His study focuses on the variables of perceived usefulness, ease of use, attitude and students' self- efficacy in learning mathematics. A group of twenty-four students of Open and Distance Education Center (ODEC) at Tribhuvan University took part in the study. The findings have shown that students have positive perceptions of the use of Moodle and are happier to learn mathematics using online tools. The author argues that Moodle if used appropriately, is helpful for the teachers and students to make teaching-learning interesting and effective.

Similarly, two articles in the volume contribute to the field of Special Needs Education. Puspa Sharma contributes to Nepal's commitment towards making schools inclusive by exploring the attitudes of teachers towards inclusive education. Drawing on her quantitative survey research, Sharma analyses the perceptions of 63 teachers from four schools. The main finding of the study is that teachers have positive attitudes towards inclusive education. In a Likert scale, ranging from 1 to 5 (highly positive), the overall attitude of teachers was found 3.32 (above average). While male teachers have slightly higher positive attitudes towards inclusive education than female teachers, younger teachers are more positive than older teachers towards the relevance of inclusive education. The trained and experienced teachers were also found more 
positive than the untrained and inexperienced ones. In addition, the teachers with some kind of disability were found to have a more positive attitude than the other groups of teachers. In other articles, Saran Hari Shrestha has explored the knowledge, awareness, and attitudes of teachers towards educating children with ASD. In a survey study among seventy-six teachers from seven special and twelve integrated schools in Kathmandu Valley, Shrestha found teachers having general ideas of ASD but lacking in-depth knowledge of broader dimensions of ASD such as awareness, understanding, attitudes, placement services, and teaching and assessment strategies for children with ASD. Most of the teachers who participated in the study thought that students with ASD should be placed in special education classrooms, not in general and inclusive classrooms. Moreover, the teachers have admitted themselves that they are ill-prepared to educate students with ASD so they are looking for special training, seminar and workshop on the learning needs of students with ASD.

The remaining three articles in this volume are written in Nepali. Tej Prasad Sigdel examines the availability of trained human resources and the adequacy of teaching materials to teach social studies in secondary schools of Nepal. Based on the analysis of data collected from the head teachers and teachers, he argues that there is a shortage of teaching materials and qualified and trained teachers to teach social studies. Sigdel concludes that one of the main reasons for students' poor achievement is lack of the trained and qualified teachers in community schools. In another article, Kushmila Acharya compares the status of various languages reported in the census data of 2001 and 2011. Her analysis has revealed that Nepal's languages fall largely into four broad families - Indo-Aryan, Sino-Tibetan, Astro-Asiastic and Dravidian. He reports 30 major languages spoken in Nepal and suggests some recommendations for the upcoming 2021 Census to address the issue of language recognition and classification. The final article written by Keshab Raj Pokhrel undertakes a comparative study of sentence structures between Bajjika and Nepali languages based on various syntactic criteria. Although both languages belong to the same Indo-Aryan family, there are substantial differences in ways sentences are constructed and grammar is used. The author argues that Bajjika speakers face difficulties and make errors in speaking and writing in Nepali as a result of syntactic inconsistencies and differences between the two languages.

Overall, this volume contributes to expanding multiple dimensions of Nepali education. A common thread of the articles indicates that school and curricular contexts of Nepal is unique and several subject-specific concerns should be taken into consideration while formulating educational policies, both at the national and local level. In specific, the articles highlight that indigenous education and languages, context-specific formative assessment practices, innovative use of ICT, inclusive education, and the production of qualified teachers and teaching materials should be core aspects of policy reforms. Overall, the volume also provides a knowledge-base to future researchers who are primarily interested in understanding the Nepali education system and its practices. 